\title{
Produtos do tamarindo (Tamarindus indica L.) no sertão pernambucano: uma experiência de extensão tecnológica
}

Tamarind products (Tamarindusindica L.) in Pernambuco's backlands: an experience of technological extension

\author{
SILVA, Maria Simão. Graduanda/Tecnologia em Alimentos \\ IF Sertão-PE - Campus Petrolina. Rua Maria Luiza de Araújo Gomes Cabral, S/N, João de Deus - Petrolina - PE - \\ Brasil. CEP: 56316-686 / Telefone: (87) 2101-4300/ E-mail: mariasimao080@gmail.com
}

CASTRO, Ruana Sertão. Graduanda/Tecnologia em Alimentos

IF Sertão-PE - Campus Petrolina. Rua Maria Luiza de Araújo Gomes Cabral, S/N, João de Deus - Petrolina - PE Brasil. CEP: 56316-686 / Telefone: (87) 2101-4300/ E-mail: ruana.paes@gmail.com

\section{CAVALCANTI, Cosme José Ramos. Especialista/Arquitetura}

Comissão de Revitalização de Caboclo. Rua Dr. Júlio Melo, 102 - Centro - Petrolina - PE - Brasil. CEP: 56300-000 / Telefone: (87) 3861-3431/ E-mail: crcavalcanti@uol.com.br

AZEVEDO, Luciana Cavalcanti de. Doutora/Engenharia Química

IF Sertão-PE - Campus Petrolina. Rua Maria Luiza de Araújo Gomes Cabral, S/N, João de Deus - Petrolina - PE Brasil. CEP: 56316-686 / Telefone: (87) 2101-4300/ E-mail: luciana.cavalcanti@ifsertao-pe.edu.br

\section{RESUMO}

O tamarindeiro (Tamarindus indica L.) é uma árvore originária da África, de onde se dispersou por vários países de clima tropical e subtropical. Trazida para o Brasil, as mudas dos tamarindeiros adaptaram-se muito bem em vários estados, especialmente no Nordeste devido ao clima semiárido. No povoado de Caboclo, município de Afrânio/PE, 26 plantas do tamarindeiro foram catalogadas. No entanto, apesar de possuir um número significativo, o consumo e aproveitamento comercial do fruto, nessa localidade, ainda não ocorrem de forma representativa. Portanto, o objetivo deste trabalho foi incentivar o beneficiamento do fruto do tamarindo, a comercialização e a propagação dos seus derivados pela comunidade. Ao longo do trabalho a comunidade foi capacitada e foram desenvolvidos alguns produtos derivados do tamarindo; para todos eles foi estabelecido fluxo de processo, formulação padrão, embalagem, custo bruto de produção e vida de prateleira, a fim de que fossem comercializados no mercado local. 0 licor e a geleia natural de tamarindo foram os produtos com melhor aceitação.

Palavras-chave: Agricultura familiar, agroindústria, processamento de fruta

\begin{abstract}
The tamarind tree (Tamarindus indica L.) is a tree originally from Africa, from where it dispersed to several countries with tropical and subtropical climate. Brought to Brazil, the tamarind seedlings have adapted very well in several states, especially in the Northeast due to the climate semi-arid. In the village of Caboclo, municipality of Afrânio/PE, 26 plants of this fruit were cataloged. However, despite having a significant number of tamarind trees, in this location the consumption and commercial use of the fruit still does not occur significantly. Therefore, the objective of this work was to encourage the processing of tamarind fruit, the commercialization and the propagation of its derivatives by the community. Throughout the work, the community was trained to deal with this fruit, some products derived from tamarind were developed and, for all of them, a process flow, standard formulation, packaging, gross cost of production and shelf life were established. After this, those products have being sold in the local market. Liquor and natural tamarind jelly were the products with the best acceptance.
\end{abstract}

keywords: Family farming, agribusiness, fruit processing 
SILVA, M. S.; CASTRO, R. S.; CAVALCANTI, C. J. R.; AZEVEDO, L. C.

Produtos do tamarindo (Tamarindus indica L.) no sertão pernambucano: uma experiência de extensão tecnológica

\section{Introdução}

Trazido ao Brasil pelos colonizadores, o fruto do tamarindo chegou até os sertões, onde os modos e costumes do povo sertanejo imprimiram vários usos, quer seja na saúde quer seja na culinária, pelas suas propriedades medicinais, sabores e facilidades de conservação. A valorização do fruto dá-se por sua transformação em derivados doces ou salgados. No entanto, apesar de possuir sabor exótico e muito característico, não é muito consumido na forma in natura devido às suas características sensoriais de elevada acidez e textura firme.

Mesmo se caracterizando como ingrediente bastante conhecido da população local, ainda é um fruto pouco explorado como matéria-prima para elaboração de produtos alimentícios em escala industrial, e as pesquisas envolvendo o fruto ainda são pouco significativas (FERREIRA, 2018). Sendo assim, é muito importante que pesquisas direcionadas à elaboração de seus derivados sejam intensificadas, para valorização e implantação do mesmo na alimentação da população, visto que apresenta excelentes propriedades nutricionais.

No povoado de Caboclo, município de Afrânio/PE, localizado na região semiárida do sertão nordestino, os tamarindeiros são árvores que fazem parte da paisagem e cultura da comunidade, pois muitos deles são centenários e estão distribuídos nas ruas, quintais e fazendas locais. No entanto, a sua exploração econômica ainda é bastante incipiente e poderia ser ainda mais intensa e estendida por todo o ano, já que existem técnicas de conservação da polpa que não requerem refrigeração ou altos investimentos em tecnologia.

Diante do cenário apresentado, foi iniciado em 1995 um trabalho de identidade e valorização do fruto do tamarindo pela ONG Comissão de Revitalização de Caboclo (CRC), juntamente com o Instituto Federal de Educação, Ciência e Tecnologia do Sertão Pernambucano (IF Sertão-PE) e outras instituições apoiadoras, que mobilizaram a comunidade em cursos com temáticas que envolviam processamento para obtenção de derivados do fruto e boas práticas de fabricação de alimentos, além de distribuição de mudas e concurso de "culinária do tamarindo", que ocorre anualmente dentro da programação da "Festa do Tamarindo", evento organizado pelas instituições envolvidas, e que já se encontra na décima sexta edição em 2020.

Como resultado de todas essas ações, percebe-se o aumento no cuidado com o plantio e manutenção dos tamarindeiros e do interesse na utilização do fruto, uma vez que já existem pequenas iniciativas de moradoras do povoado no sentido de elaboração e venda de pratos que utilizam o tamarindo como ingrediente, sendo essas iniciativas, ainda, limitadas ao período de safra (agosto e setembro).

Além disso, para garantir o fornecimento de polpa de tamarindo e seus derivados durante todo o ano, foi proposto em 2019 um projeto de elaboração em escala piloto de quatro produtos, sendo eles: Polpa concentrada (armazenada em temperatura ambiente), fruto descascado e embalado a vácuo, geleia e licor. 0 referido projeto faz parte do Programa de Apoio ao Empreendedorismo Inovador (PAEmpl) do IF Sertão-PE e reforça ainda mais as ações iniciadas pelas instituições parceiras.

Este artigo tem como objetivo, portanto, registrar as ações realizadas e as experiências da 
SILVA, M. S.; CASTRO, R. S.; CAVALCANTI, C. J. R.; AZEVEDO, L. C.

Produtos do tamarindo (Tamarindus indica $L$.) no sertão pernambucano: uma experiência de extensão tecnológica

equipe do IF Sertão-PE em mais de uma década de trabalho de extensão tecnológica realizado na comunidade de Caboclo/PE. Todo o detalhamento técnico relativo aos produtos e processos, resultantes da fase de pesquisa científica, será feito em publicação posterior.

\section{Importância nutricional do tamarindo}

O tamarindo é o fruto do tamarindeiro, caracterizado por ser uma vagem alongada, protegida por casca pardo-escura (Figura 1), lenhosa e quebradiça, contendo de 1 a 5 sementes lisas achatadas, envolvidas por uma polpa seca, de cor marrom e de sabor ácido-adocicado (PEREIRA et al., 2011).

Figura 1 - Fruto do tamarindo

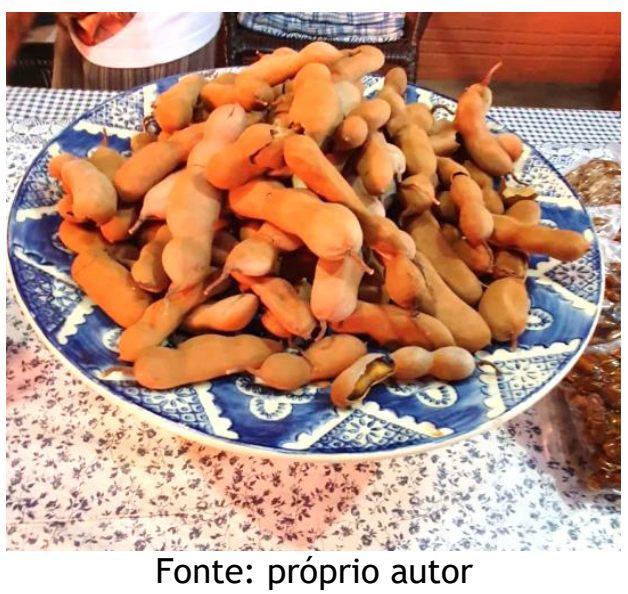

É bastante conhecido da população por apresentar propriedades laxantes e afrodisíacas (KURU, 2014). Como apresenta uma polpa com baixo teor de umidade (aproximadamente 38\%), concentra excelentes componentes nutricionais que vão além das propriedades citadas.

Trata-se de um fruto com elevado teor de proteínas $(4,12 \%)$, glicídios $(23,84 \%)$, elementos minerais (2,96\%) como potássio, fósforo, cálcio, magnésio e ferro, e vitaminas A, B e C (FERREIRA, 2018). Rica em açúcares e fibras solúveis, a polpa possui, também, quantidades de ácidos orgânicos dos quais, grande parte se constitui de ácido tartárico, e que conferem a este fruto sabor azedo adocicado, mesmo quando maduro (FERREIRA, 2018; SANTOS et. al., 2019).

Lim et al. (2013) relataram em seus estudos que os extratos de polpa de tamarindo apresentaram também propriedades antioxidantes e de combate ao colesterol, uma vez que foram detectados expressivos teores de compostos fenólicos (LIM et. al., 2013). Os antioxidantes contribuem para a eliminação de espécies reativas de oxigênio, inibindo e reduzindo as lesões causadas pelos radicais livres nas células, atuando na prevenção de doenças como o câncer (VIEIRA et al., 2011).

Em trabalho recente, Leite et. al. (2019) demonstraram que até mesmo o resíduo desidratado do processamento da polpa de tamarindo pode ser um potencial ingrediente funcional para a indústria de alimentos, uma vez que foram encontrados: 5,26\% proteína, 8,76\% gordura total, 2,94\% cinzas, 35,98\% fibra bruta e 2,82\% de acidez total titulável, expresso em ácido tartárico. Além 
SILVA, M. S.; CASTRO, R. S.; CAVALCANTI, C. J. R.; AZEVEDO, L. C.

Produtos do tamarindo (Tamarindus indica L.) no sertão pernambucano: uma experiência de extensão tecnológica

disso, o resíduo apresentou também elevadas concentrações em fenólicos totais e alta capacidade antioxidante, avaliadas pelos ensaios do DPPH e ABTS, respectivamente (LEITE et. al., 2019).

Por apresentar nutrientes tão importantes, é frequentemente utilizado por algumas comunidades indígenas africanas para complementar as necessidades alimentares, especialmente em tempos de escassez (EBIFA-OTHIENO et. al., 2017).

\section{Importância industrial do tamarindo}

O fruto do tamarindo pode ser integralmente utilizado na indústria de transformação. Vários produtos podem ser obtidos, nas indústrias farmacêuticas, cosméticas, têxteis, de novos materiais e, principalmente, alimentícias (DE CALUWÉ 2010 et. al.; PEREIRA et al., 2011).

Existem relatos do uso da sua casca como material adsorvente na indústria química e da semente como fonte de hidrocolóides, gordura insaturada ou aminoácidos importantes. De acordo com Luiza e Neuza (2011), o óleo das sementes apresenta alta estabilidade oxidativa e significativo teor de tocoferol e ácido linolênico, considerado um ácido graxo essencial (LUZIA \& NEUZA, 2011).

Suas fibras também já foram testadas em compósitos poliméricos, como reforço em matriz de poliéster insaturado, otimizando as propriedades mecânicas do material (BINOJ et. al., 2017).

A polpa do fruto, fração principal em foco deste trabalho, pode ser utilizada na fabricação de doces, sorvetes, licores, bebidas fermentadas, sucos concentrados, geleias, condimentos e moIhos (GARCÍA et al., 2012; PEREIRA et al., 2011; SANTOS et. al., 2019). O sabor amargo e ácido do fruto o torna ingrediente versátil para uso em formulações doces ou salgadas (LEITE et. al, 2019).

0 rendimento das frações que compõem o fruto é de aproximadamente 30\% para a polpa, $30 \%$ para cascas e fibras e 40\% de sementes (FAVET; FRIKART; POTIN, 2011). 0 rendimento em polpa pode parecer baixo, se comparado a outras frutas utilizadas na indústria de alimentos, cujo percentual deve ser, em geral, de no mínimo $70 \%$ para tornar o processo economicamente viável. Deve ser levado em conta, no entanto, que por ser uma fruta naturalmente desidratada, requer adição de água no processo de despolpamento, o que incrementa o volume de polpa e equilibra o balanço de massa final.

É importante destacar também a facilidade de conservação desta matéria-prima, resultante do teor de ácidos orgânicos presentes. A existência do ácido tartárico, cítrico e málico conferem-lhe um $\mathrm{pH}$ de 2,6, bem abaixo do $\mathrm{pH}$ considerado de segurança para os alimentos industrializados, que é de 4,5 (LEITE et. al., 2019). Com este pH, associado ao baixo teor de água contido na polpa, os frutos do tamarindo podem ser armazenados por longos períodos em sistema de refrigeração ou mesmo à temperatura ambiente.

\section{Importância socioeconômica e cultural do tamarindo para a comunidade do Caboclo}

O povoado de Caboclo está localizado a $9 \mathrm{Km}$ de Afrânio/PE, município que faz fronteira 
SILVA, M. S.; CASTRO, R. S.; CAVALCANTI, C. J. R.; AZEVEDO, L. C.

Produtos do tamarindo (Tamarindus indica $L$.) no sertão pernambucano: uma experiência de extensão tecnológica

entre os Estados de Pernambuco e Piauí. Faz parte da região semiárida do sertão pernambucano, no Nordeste brasileiro, com clima seco e chuvas espaças (Guia Geográfico - Pernambuco, 2020).

A maior parte dos moradores pratica agricultura de subsistência, cultivando culturas anuais como milho e feijão.

Os tamarindeiros começaram a fazer parte do cenário do povoado no início do século XIX, quando os primeiros moradores resolveram plantá-los em frente às suas casas, atendendo à crendice popular de que a planta traria proteção às suas famílias. Por apresentarem sistema radicular profundo, resistiram às secas prolongadas da região e, desta forma, se mantiveram intactas até os dias de hoje, servindo de estímulo ao plantio de muitas outras mudas pela comunidade (COSTA et. al., 2012).

Atualmente existem três desses antigos tamarindeiros, cujas sombras são intensivamente aproveitadas pelas famílias do lugar, representando para essas pessoas o ponto de encontro para uma boa conversa, a sombra para o descanso, o abrigo para as brincadeiras infantis, o palco para apresentações culturais. Enfim, fazem parte do cenário e do dia-a-dia dos moradores.

0 tamarindeiro foi fonte de inspiração aos poetas Gregório Menezes e Mozart C. Figueiredo (obra: Debaixo do Tamarindo), aos pintores Bernadeth Cavalcanti, Otoniel Fernandes Neto, Jorge Sairaf, E. Duarte, Alberto Simões e outros tantos. Também outros artistas do cinema "Memorial Maria Moura" (filme rodado em Caboclo, baseado no clássico de Raquel de Queiroz) e da televisão como Aldy Carvalho em vídeo veiculado ainda nos dias de hoje pela TV Grande Rio de Petrolina, com direção de Luciano Peixinho. Músicos e violeiros regionais como Hosterninho do Acordeon e Gonzaga Neto fizeram suas composições inspiradas nessas árvores. Chefs de cozinha e quituteiras fizeram e continuam fazendo maravilhosas guloseimas com o fruto.

Desde a realização da primeira Festa do Tamarindo em 1995, debaixo do Velho tamarindeiro sesquicentenário, quando foi fundada a ONG Comissão de Revitalização de Caboclo (CRC), que vêm sendo difundidos os seus produtos derivados e estimulando o plantio através da distribuição de mudas de novas espécies melhoradas, aportando novas oportunidades de trabalho e renda para a comunidade.

\section{Ações de extensão tecnológica desenvolvidas no projeto pela equipe do IF Sertão-PE}

\section{Atividades de sensibilização para consumo e uso do tamarindo}

De acordo com o Centro Brasileiro de Relações Internacionais (CEBRI), a integração entre os centros de ensino e pesquisa regionais, ONGs e governo para criação de produtos e serviços, gerando empreendimentos sustentáveis é o movimento fundamental para a consolidação da extensão tecnológica em uma determinada região (CEBRI, 2012).

A extensão tecnológica ocorre quando as Universidades e Institutos conseguem transformar a produção acadêmica em benefícios para a atividade produtiva da região, quando se cria um elo 
SILVA, M. S.; CASTRO, R. S.; CAVALCANTI, C. J. R.; AZEVEDO, L. C.

Produtos do tamarindo (Tamarindus indica L.) no sertão pernambucano: uma experiência de extensão tecnológica

entre centros de ensino e pesquisa regionais, empresas e governo, que fomentam um ambiente de estímulo a pequenas e micro empresas que, sozinhas, não teriam condições de se desenvolver (ISAAC et. al., 2012; CEBRI, 2012).

As ações de pesquisa e extensão empreendidas pela equipe de docentes e discentes do IF Sertão-PE na comunidade de Caboclo vem sendo direcionadas prioritariamente à sensibilização para a importância da exploração econômica do fruto do tamarindo, mas envolve também outras atividades técnicas e de reforço na identidade cultural do local.

A seguir, serão apresentadas apenas as ações desenvolvidas pela equipe do IF Sertão-PE e que tiveram maior impacto inicialmente sobre a apropriação do fruto pela comunidade (Figuras 2 a 7).

Figura 2 - Turma do curso "Produtos do tamarindo", ministrado por docentes e alunos do IF Sertão-PE em 2006.

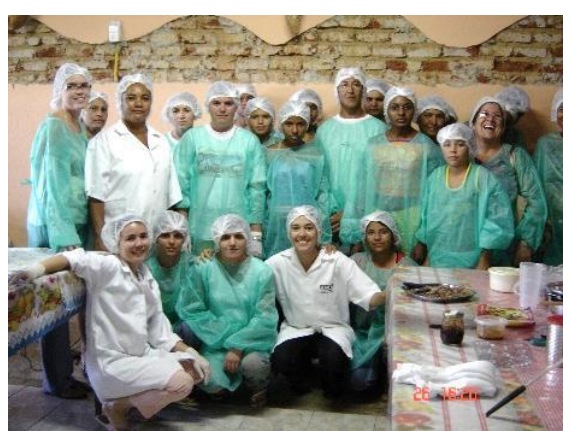

Fonte: próprio autor

Figura 3 - Produtos do tamarindo elaborados no curso ministrado por docentes e alunos do IF Sertão-PE em 2007.

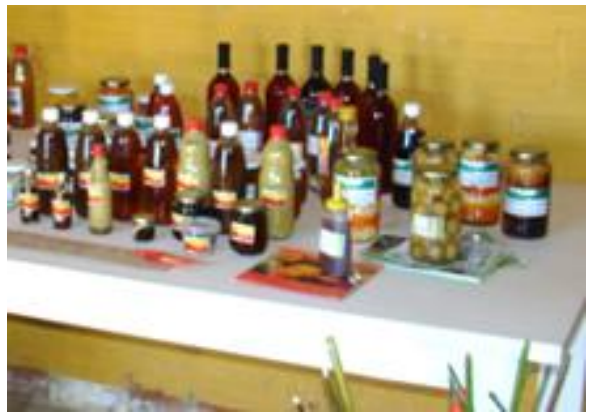

Fonte: próprio autor

Figura 4 - Curso de Licores ministrado por docentes e alunos do IF Sertão-PE em 2009.

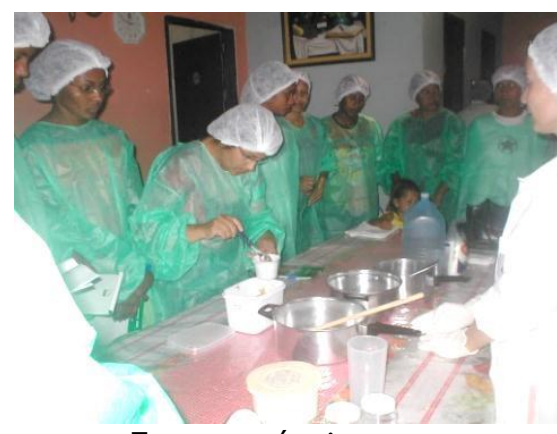

Fonte: próprio autor 
SILVA, M. S.; CASTRO, R. S.; CAVALCANTI, C. J. R.; AZEVEDO, L. C.

Produtos do tamarindo (Tamarindus indica $L$.) no sertão pernambucano: uma experiência de extensão tecnológica

Figura 5 - Concurso de "Culinária do tamarindo" - edição 2011.

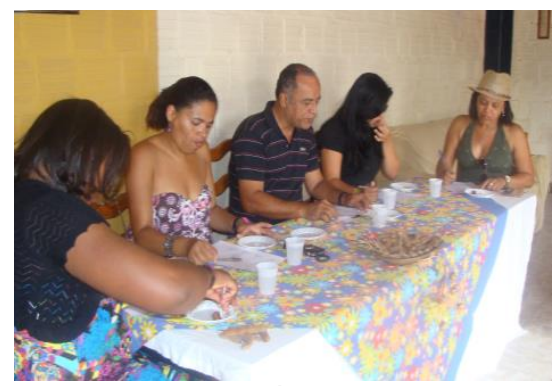

Fonte: próprio autor

Figura 6 - Gincana cultural com crianças da comunidade à sombra do tamarindeiro em 2018.

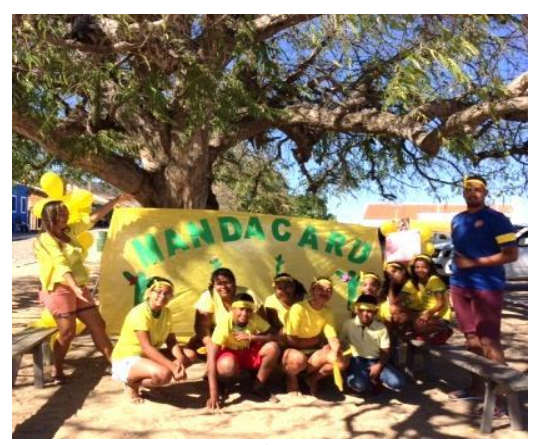

Fonte: próprio autor

Figura 7 - Comunidade e visitantes em momento de oração pelo tamarindeiro, em 2018.

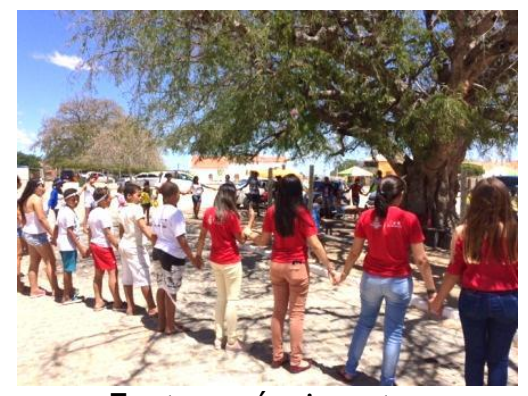

Fonte: próprio autor

- 2006 - Curso "Produtos do tamarindo I" (Figura 2);

- 2007 - Curso “Produtos do tamarindo II” e exposição de produtos elaborados (Figura 3);

- 2009 - Curso de elaboração de licores (Figura 4);

- 2006 a 2019 - Concurso de culinária do tamarindo (Figura 5)

- 2018 - Gincana cultural com crianças da comunidade à sombra do tamarindeiro (Figura 6);

- 2018 - Oração pela árvore do tamarindo (Figura 7);

- 2019 - Mapeamento dos tamarindeiros existentes no povoado;

- 2019 - Execução de projeto para elaboração e comercialização de produtos derivados do tamarindo (PAEmpl) (Figuras 8 e 9).

As primeiras iniciativas buscaram ressaltar a importância do fruto como alimento e como 
SILVA, M. S.; CASTRO, R. S.; CAVALCANTI, C. J. R.; AZEVEDO, L. C.

Produtos do tamarindo (Tamarindus indica L.) no sertão pernambucano: uma experiência de extensão tecnológica

matéria-prima em receitas das mais simples às mais sofisticadas, de forma que houvesse interesse entre os participantes por algum tipo de aplicação do fruto, já que na comunidade os tamarindos eram sequer colhidos dos pés, por absoluta falta de interesse. Para isso, foram ministrados alguns minicursos no próprio povoado.

Ao se perceber que havia um aumento no envolvimento dos moradores com o fruto, optouse por promover o Concurso de "Culinária do Tamarindo", no qual as receitas desenvolvidas pelas próprias mulheres da comunidade foram submetidas a uma banca avaliadora formada por jornalistas, chefs de cozinha, e outros profissionais envolvidos com o turismo gastronômico. Todas as receitas concorrentes foram arquivadas e irão compor um livro de receitas para registrar a memória gastronômica local.

Todas as ações realizadas desde 1995 até 2019 fizeram parte das programações da Festa do Tamarindo, evento organizado pela CRC, que conta com o apoio do IF Sertão-PE e outras instituições.

\section{Atividades de elaboração e venda de produtos derivados do tamarindo.}

Ao passar dos anos, a colheita e consumo do fruto passou a ser uma atividade comum na comunidade e novas mudas de tamarindeiro foram plantadas. Diante dessa nova realidade, foi feita então, pela equipe do IF Sertão-PE, uma proposta de que os frutos pudessem ser beneficiados em escala semi-industrial e comercializados, com intuito de gerar renda complementar para as cinco mulheres engajadas no projeto (Figura 8).

Figura 8 - Elaboração de produtos do tamarindo com moradoras do povoado, no projeto PAEmpl - 2019.

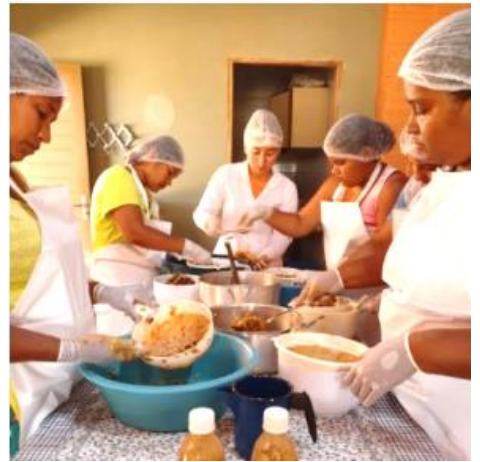

Fonte: próprio autor

Os produtos escolhidos para serem desenvolvidos nesta etapa piloto foram: polpa concentrada, geleia, licor e fruto descascado e embalado a vácuo (Figura 10). Para todos eles foi definido fluxo de processo, formulação padrão, embalagem, custo bruto de produção e vida-deprateleira.

Os produtos foram expostos em feiras agropecuárias regionais como a $3^{\mathrm{a}}$ Expoleite (Afrânio/PE) e $8^{0}$ SemiáridoShow (Lagoa Grande/PE) , onde foram, também, comercializados. 


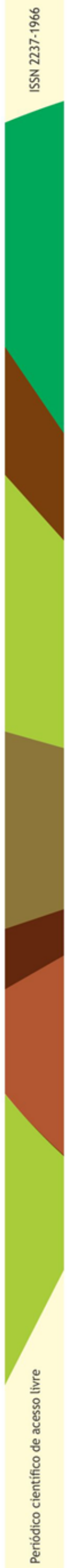

SILVA, M. S.; CASTRO, R. S.; CAVALCANTI, C. J. R.; AZEVEDO, L. C.

Produtos do tamarindo (Tamarindus indica L.) no sertão pernambucano: uma experiência de extensão tecnológica

Figura 9 - Produtos do tamarindo produzidos e comercializados no projeto PAEmpl - 2019.

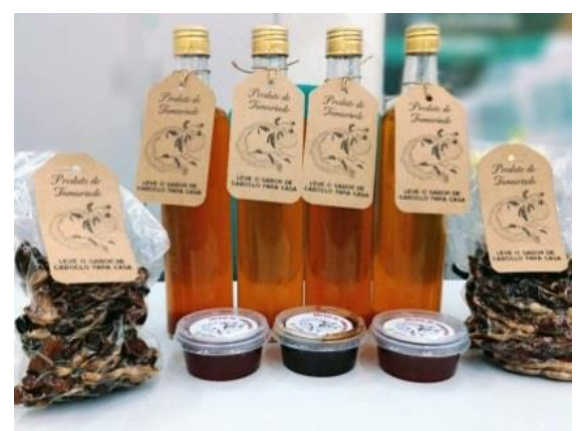

Fonte: próprio autor

\section{Mapeamento dos tamarindeiros do povoado de Caboclo/PE}

O mapeamento de árvores em determinada localidade pode ser realizado através de levantamento com sistemas que utilizam tecnologia de varredura terrestre, levantamento topográfico, levantamento com dispositivos móveis, imagens de satélite, etc. (BARBOSA et. al, 2018). Para o mapeamento dos tamarindeiros do povoado de Caboclo a equipe optou pela utilização de imagens de satélite devido ao seu baixo custo quando comparado aos métodos citados acima. Com o auxílio da imagem de satélite do povoado adquirida no Google Earth, a equipe fez uma conferência in loco, certificando-se da quantidade e localização de cada árvore, sendo identificadas 26 plantas na localidade (Figura 10).

Figura 10 - Mapeamento dos 26 tamarindeiros existentes no povoado de Caboclo/PE

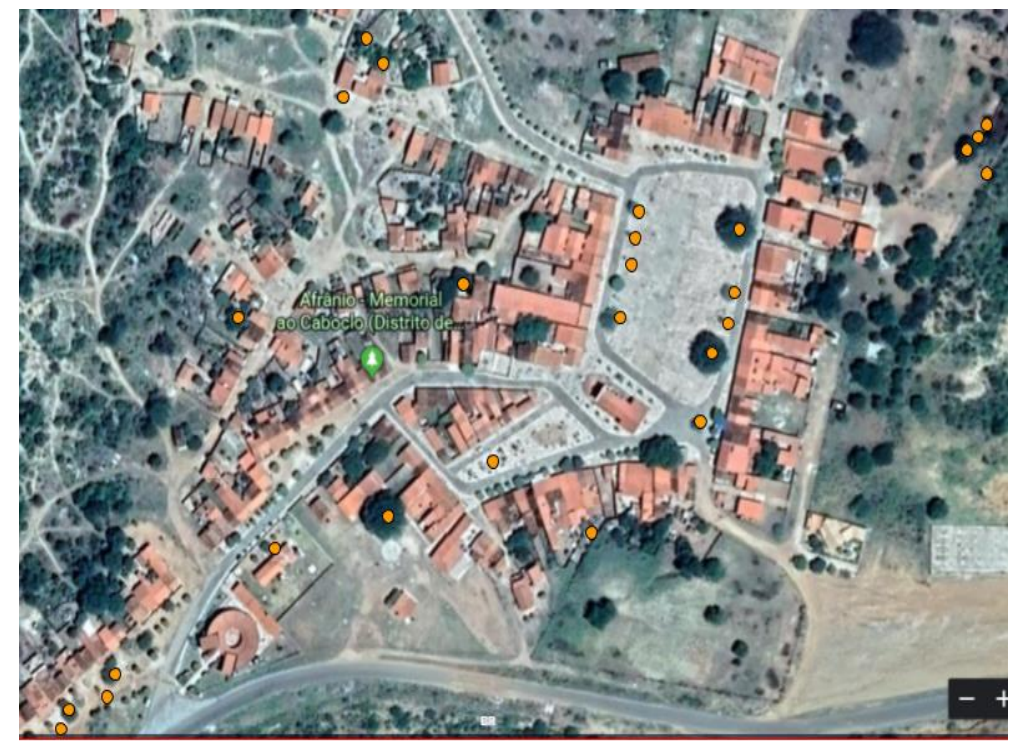

Fonte: Google Earth e dados da pesquisa.

Árvores de tamarindo identificadas durante o mapeamento 
SILVA, M. S.; CASTRO, R. S.; CAVALCANTI, C. J. R.; AZEVEDO, L. C.

Produtos do tamarindo (Tamarindus indica L.) no sertão pernambucano: uma experiência de extensão tecnológica

\section{Principais resultados}

A transformação de conhecimento acadêmico em produtos com possibilidade de chegar ao mercado e gerar renda, especialmente em comunidades que sobrevivem da agricultura familiar é uma prática cada vez mais necessária e difundida no Brasil (ISAAC et. al., 2012). Iniciativas como essas têm sido reconhecidamente as de resultados mais expressivos aos empreendimentos de pequeno porte, por tornar viável o acesso à pesquisa e ao desenvolvimento (CEBRI, 2012).

Muitos aspectos positivos foram observados durante esses anos de trabalho junto à comunidade do povoado de Caboclo, incluindo a própria participação da comunidade como sujeitos nas atividades realizadas, e não somente como espectadores.

Também é notório o interesse da população pelo fruto e pelas oportunidades econômicas atreladas a ele. 0 fruto que antes permanecia esquecido na árvore sem sequer ser colhido, hoje é disputado com maior intensidade nas 26 plantas identificadas.

A parceria da ONG CRC com o IF Sertão-PE trouxe os conhecimentos e técnicas de utilizações nos produtos derivados apresentados nos concursos e feiras, sendo inclusive catalogadas mais de 150 receitas, algumas em publicação bilíngue, e divulgados na imprensa regional e nacional, surgindo a necessidade de organizar uma publicação com todo o receituário testado e aprovado. Além disso, foram produzidos documentos como matérias de jornais, apostilas, artigos e livros que registram as soluções apresentadas pelo projeto, incutindo o orgulho entre os moradores do povoado sobre seus valores tradicionais, para que sejam utilizados por muitas gerações.

Do ponto de vista de produção em escala semi-industrial, é possível inferir que a quantidade de árvores existentes poderia suprir o volume de matéria-prima para uma pequena agroindústria, uma vez que a produção por fruto pode ser de 150-500 kg de vagem por árvore saudável por ano, em árvores com 20 anos de idade (PEREIRA et. al., 2011). Se considerarmos um valor de produção de $200 \mathrm{Kg}$ do fruto por árvore, por safra, a produção local seria de aproximadamente 5 toneladas/ano, viabilizando a instalação de uma unidade de processamento.

A produção em maior escala foi validada quanto aos produtos elaborados e comercializados na fase piloto, pois os produtos obtiveram boa aceitação comercial. A maior aceitação foi observada para o licor de tamarindo e para a geleia, porém todos os produtos tiveram bom volume de venda e demonstram serem promissores para o mercado.

\section{Conclusões}

Todas essas ações vêm colaborando no fortalecimento da identidade cultural e no incentivo aos moradores da comunidade de Caboclo para trabalhar com um fruto típico da região, bem como conscientizá-los da importância econômica dos produtos para a região, já que existe a possibilidade de aumento na economia local em função da renda extra adquirida com a venda dos produtos.

0 resgate cultural, vindo através das Festas do Tamarindo, também é notável. Grupos folclóricos, cantores, orquestras, artesãos, caravanas de turistas e muitos visitantes do Nordeste, participam da festa que já está no Calendário Turístico do Estado de Pernambuco, acontecendo 
SILVA, M. S.; CASTRO, R. S.; CAVALCANTI, C. J. R.; AZEVEDO, L. C.

Produtos do tamarindo (Tamarindus indica L.) no sertão pernambucano: uma experiência de extensão tecnológica

sempre no último final de semana do mês de Agosto.

0 evento conta com o apoio da municipalidade, de diversas instituições, além do patrocínio de empresas regionais, por ser uma grande atração.

o impacto dessas atividades vem contribuindo, de forma direta ou indireta com o comportamento dos moradores da comunidade bem como permitiu a valorização do fruto pelos moradores dando-lhes oportunidade de reforço na renda familiar mensal.

\section{Agradecimentos}

Os autores agradecem a todas as instituições parceiras no desenvolvimento deste projeto, em especial à Comissão de Revitalização de Caboclo, à imprensa regional e todas as pessoas que, de forma voluntária, enriqueceram esse projeto.

\section{Referências}

BARBOSA, R. L.; GALLIS, R. B. A.; HIRAGA, A. K.; SILVA, F. A. Quantificação e georreferenciamento semiautomático de árvores urbanas. REVSBAU, Curitiba - PR, v13, n.4, p. 41-53, 2018.

BINOJ, J.S ; EDWIN RAJ, R ; DANIEL, B.S.S. Comprehensive characterization of industrially discarded fruit fiber, Tamarindusindica $L$. as a potential eco-friendly bio-reinforcement for polymer composite. Journal of Cleaner Production, 2017, Vol.142, pp.1321-1331

CEBRI. Centro Brasileiro de Relações Internacionais. Extensão Tecnológica: Estudo de Benchmarking Internacional Micro e Pequenas Empresas. Rio de Janeiro, 2012.

COSTA, E.; FERREIRA, A. F. A.; SILVA, P. N. L.; NARDELLI, E. M. V. Diferentes composições de substratos e ambientes protegidos na formação de mudas de pé-franco de tamarindeiro. Rev. Bras. Frutic., Jaboticabal - SP, v. 34, n. 4, p. 1189-1198, 2012.

DE CALUWÉ, E.; HALAMOVÁ, K.; VAN DAMME, P. Tamarindus indica L.: A review of traditional uses, phytochemistry and pharmacology Afrika Focus, Vol.23(1), pp.53-83, 2010.

EBIFA-OTHIENO, E.; MUGISHA, A.; NYEKO, P.; KABASA, J. D. Knowledge, attitudes and practices in tamarind (Tamarindus indica L.) use and conservation in Eastern Uganda. Journal of Ethnobiology and Ethnomedicine 13:5, 2017.

FAVET, R., FRIKART, M.-J., POTIN, J. La valorisation du tamarin. Richesses et potentialités des agroressources dans les PED UE 9 - IAAS 3. Montpellier SupAgro, 2011.

FERREIRA, C. F.; Caracterização integral de frutos tamarindo (Tamarindus indica L.) do cerrado de Goiás, Brasil e aplicação em produtos drageados. Dissertação de Mestrado, UFG, Goiânia, 2018.

Guia Geográfico - Pernambuco. Disponível em: https://www.brasilturismo.com/pernambuco/mapa.htm. Acesso em: 21/04/2020.

ISAAC, P. H.; BERMUDEZ, L. A.; DESSEN, M. C.; AFFIUNE, A. A. Extensão Tecnológica - uma possibilidade viável com relevantes impactos socioeconômicos. Anais da Semana Universitária UNB, 2012.

KURU, P. Tamarindus indica and its health related effects. Asian Pacific Journal of Tropical 
SILVA, M. S.; CASTRO, R. S.; CAVALCANTI, C. J. R.; AZEVEDO, L. C.

Produtos do tamarindo (Tamarindus indica L.) no sertão pernambucano: uma experiência de extensão tecnológica

Biomedicine, Hainan, v. 4, n.9, p. 676-681, 2014.

LEITE, C. X. dos S.; BORGES, M. V.; SANTOS, M. R. C.; SANTOS, I. A.; SILVA, M. V. Subproduto de tamarindo: caracterização físico-química, fenólicos totais e capacidade antioxidante. Rev. Higiene Alimentar, v.33, p.1516, 2019.

LIM, C. Y.; JUNIT, S. M.; ABDULLA, M. A.; AZIZ, A. A.In vivo biochemical and gene expression. Analyses of the antioxidante activities and hypocholesrolaemic properties of tamarindus indica fruit pulp extract. Plos One, California, v. 8, n. 7, e70058, 2013.

LUZIA, D. M. M.; NEUZA, J. Antioxidant activity, fatty acid profile and tocopherols of Tamarindus indica L. seeds. Food Science and Technology, Vol.31(2), pp.497-501.2011.

PEREIRA, P. C.; MELO, B.; FRANZÃO, A. A.; ALVES, P. R. B. (2011). A cultura do tamarindeiro (Tamarindus indica L.). Universidade Federal de Uberlândia, 2011. In: http://www. fruticultura.iciag.ufu.br/tamarindo.htm. Acesso em: 22/03/2020.

SANTOS, E. A. da S.;SANTOS, J. M.; SANTOS, T. S. S.; CORREA, S. J. P.; REIS, M. F. T. Desenvolvimento e caracterização da bebida alcoólica fermentada de tamarindo (Tamarindus indica). Rev. Higiene Alimentar, v. 33, p.3370, 2019.

VIEIRA, L. M.; SOUSA, M. S. B.; MANCINI FILHO, J.; LIMA, A. Fenólicos totais e capacidade antioxidante in vitro de polpas de frutos tropicais. Revista Brasileira de Fruticultura, Jaboticabal, v. 33, n. 3, p. 888-897, 2011. 